Disponível em

http://www.anpad.org.br/rac

RAC, Rio de Janeiro, v. 19, n. 3, art. 3, pp. 336-354, Maio/Jun. 2015 http://dx.doi.org/10.1590/1982-7849rac20151796

$(\mathrm{cc})$ EY-NG

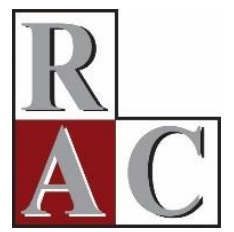

\title{
Transmissão do Conhecimento Prático como Intencionalidade Incorporada: Etnografia numa Doceria Artesanal
}

Practical Knowledge Transmission as Embodied Intentionality: Ethnography in an Artisanal Confectionary Shop

Marina Dantas de Figueiredo Universidade de Fortaleza - UNIFOR

Neusa Rolita Cavedon Universidade Federal do Rio Grande do Sul - UFRGS

Artigo recebido em 17.12.2013. Última versão recebida em 22.11.2014. Aprovado em 25.11.2014. 


\title{
Resumo
}

Neste artigo, assumimos que a relação dos praticantes com aquilo que se pode chamar de contexto faz surgir a necessidade de problematizar as origens e os mecanismos de manutenção das práticas e das comunidades de prática. Tendo por base os dados de pesquisa etnográfica em uma fábrica de doces em Pelotas, Rio Grande do Sul, buscamos mostrar como a transmissão de um saber-fazer artesanal é fruto de uma intencionalidade incorporada. A partir das vivências e observações sobre as relações entre uma mestra doceira e seus funcionários, percebemos que o processo de transmissão do saber-fazer característico dessa prática artesanal está condicionado a certa intencionalidade incorporada, associada a questões de gênero, etnia e trajetória de vida. Identificamos que, muito embora a prática em questão oriente um sistema produtivo relativamente simples, o fato de a maior parte das pessoas envolvidas não alcançar o domínio pleno sobre o saber-fazer que a norteia sinaliza que as relações de transmissão desse saber incorporado envolvem questões mais complexas do que a disposição ou o interesse para ensinar ou aprender uma prática.

Palavras-chave: corpo; intencionalidade incorporada; saber-fazer; artesanato; etnografia.

\begin{abstract}
In this article we assume that the relationship of practitioners with what might be called context gives rise to the need to problematize the origins and mechanisms of maintenance of practices and communities of practice. Based on data from ethnographic research in a candy factory in Pelotas, Rio Grande do Sul, we seek to show how the transmission of practical know-how is the result of embodied intentionality and analyze how this contributes to the perpetuation of certain social, cultural and historical structures. From the experiences and observations about the relationship between a master baker and her staff, we perceive that the process of transference of the knowhow that is characteristic of this craft is conditioned by a specific incorporated intentionality associated with gender, ethnicity and life trajectory. We found that although the practice in question guides a relatively simple production system, the fact that most of the people involved do not achieve full mastery over the know-how that guides it indicates that transference relationships of this embodied knowledge involve more complex issues than the willingness or interest to teach or learn a practice.
\end{abstract}

Key words: body; embodied intentionality; know-how; craft; ethnography. 


\section{Introdução}

Desde que as teorias da prática passaram a atrair a atenção dos estudiosos das organizações, diferentes correntes filosóficas - tais como a tradição marxista, a fenomenologia, o interacionismo simbólico e o legado de Wittgenstein (Nicolini, Gherardi, \& Yanow, 2003) - têm alimentado as pesquisas reunidas sob o epíteto de estudos baseados na prática (practice-based studies). Embora não pactuem de uma definição compartilhada do termo prática (Gherardi, 2009a), muitos desses estudos têm em comum o interesse por compreender os processos organizacionais cotidianos que permitem a reprodução da organização através da repetição de seus elementos relacionais e normativos (Gherardi \& Nicolini, 2003; Gomez, Bouty, \& Drucker-Godard, 2003; Suchman, 2000).

Nos estudos sobre aprendizagem organizacional, o conceito de práticas proporcionou uma compreensão crítica sobre o modo como o conhecimento é socialmente produzido. Em 2001, a publicação do artigo Knowledge and organization: a social-practice perspective, de John Seely Brown e Paul Duguid, enfatizou que o conhecimento organizacional que emerge nas comunidades de prática não tem origem no indivíduo, nem na comunidade, mas na imersão de ambos em "estruturas maiores" (Brown \& Duguid, 2001, p. 209). Esse achado, reforçado posteriormente por outros autores (Gherardi, 2009b; Roberts, 2006), culmina em uma mudança de perspectiva que vem a problematizar o contexto social, material e histórico de origem da prática e da comunidade que se forma e define a partir dela. Há que se levar em conta, portanto, que o envolvimento de um praticante com uma prática, bem como a definição de sua identidade como praticante, é uma questão de engajamento compartilhado e coletivamente elaborado por essa comunidade.

Os estudos sobre o tema não se referem somente àquilo que as pessoas fazem cotidianamente, mas também ao significado de suas ações, bem como seu impacto sobre arranjos sociomateriais (Gherardi, 2009b). A investigação se concentra na regularidade das ações, no padrão que organiza as atividades e em uma compreensão compartilhada capaz de assegurar que os praticantes estejam aptos a reproduzi-las através do tempo. Isso implica considerar os aspectos estruturais da comunidade em que a prática é cultivada e compartilhada, bem como compreender a força estruturante dos agentes que conduzem as práticas por circuitos de reprodução e atualização em suas performances cotidianas.

A relação dos praticantes com as circunstâncias materiais, culturais e históricas faz surgir a necessidade de problematizar as estruturas das práticas e das comunidades. Apesar disso, Gherardi (2009b) assinala que "o tema de como a reprodução das práticas contribui para a produção da ordem social no contexto das práticas de trabalho tem sido negligenciado pelos estudos baseados na prática (practice-based studies)" (p. 536). Conforme a autora, essa postura tem impedido a consecução de trabalhos que contemplem as questões de como as práticas são socialmente sustentadas e quais são os meios de transmissão do conhecimento social. Para o estudo dos processos de aprendizagem organizacional, a compreensão do contexto de produção e reprodução das práticas pode revelar como o conhecimento característico da cultura repousa nas pessoas tanto quanto no ambiente e nas circunstâncias históricas. A partir dessa lacuna identificada por Gherardi (2009b), entendemos que o problema da transmissão do conhecimento prático pode ser melhor compreendido se analisarmos como restrições e possibilidades são inculcadas na conduta dos praticantes no seio de uma comunidade.

Argumentamos que a transmissão de saberes incorporados é menos resultado de uma escolha racional do que a expressão de significados ancorados nas estruturas e nas práticas estruturantes de uma comunidade. Portanto o processo de incorporação do conhecimento não é algo que possa ser descrito como assimilação ou aquisição. Para compreendê-lo, é preciso identificar o contexto original das práticas e compreender os motivos históricos para o engajamento das pessoas. A incorporação (no sentido da inculcação) do conhecimento prático se estabelece, então, por meio de uma dialética temporal complexa, na qual as estruturas sociais e os componentes experienciais associados a uma prática do passado são atualizados e revividos por indivíduos no presente, em um processo no qual se busca, de alguma maneira, reproduzir as disposições do habitus e as peculiaridades do contexto ao qual a prática está associada. 
Nosso objetivo para este artigo é mostrar como a transmissão de um conhecimento prático é fruto de uma intencionalidade incorporada (Bourdieu, 2000; Merleau-Ponty, 2005; O'Connor, 2005). A ideia de intencionalidade incorporada consiste no estado de consciência que surge da percepção e da relação imediata do corpo com as estruturas sociais e que não pode ser descrito propriamente como racional, nos termos da separação cartesiana entre mente (o lócus da razão) e corpo (o lócus da sensação). A ideia de uma intencionalidade incorporada surge, na teoria de Bourdieu (2001, p. 174), como "uma espécie de coincidência necessária - o que lhe confere a aparência de uma harmonia preestabelecida - entre um habitus e um campo".

Subsidiando esse entendimento está, portanto, o conceito de habitus, que, para Bourdieu (2001), corresponde a um sistema de disposições resultantes da interiorização de estruturas sociais, que, de tão inculcadas nos indivíduos, fazem-se passar por atitudes naturais. Enquanto produto da incorporação de um campo e da ordem social que o orienta, o habitus engendra práticas completamente ajustadas a essa ordem. Esse conceito ganha importância na argumentação que almejamos desenvolver neste artigo porque é capaz de mediar as inter-relações ação/estrutura e indivíduo/sociedade, bem como explicar como as práticas estão condicionadas a circunstâncias de existência. Além disso, o habitus enseja uma lógica a partir da prática, uma intenção que surge e expressa-se na ação. Por intencionalidade incorporada, queremos descrever, a partir de uma perspectiva fenomenológica, a manifestação de uma forma de conhecimento sem consciência ou de intencionalidade sem intenção (Bourdieu, 2000).

Para tanto, investigamos o processo de transmissão de uma prática cultural tradicional: a elaboração de doces artesanais na cidade de Pelotas, Rio Grande do Sul. A justificativa para o estudo reside no fato de que a transmissão de um saber-fazer artesanal na relação entre mestre e aprendiz está indissociavelmente atrelada às suas histórias individuais e às histórias dos grupos sociais dos quais são originários - ou seja, às disposições do habitus a que estão vinculados e às características do contexto no qual esse habitus foi forjado. Ainda que as circunstâncias de sua reprodução mudem e que os praticantes atuais olvidem suas origens, defendemos que certas práticas artesanais que podem ser consideradas tradicionais se mantêm fundamentalmente ligadas a um cerne, enraizadas no corpus social e inscritas nos circuitos de uma memória coletiva (Bosi, 1987), por meio da tradição de uma comunidade de praticantes.

Através de pesquisa etnográfica, constatamos que a transmissão do saber-fazer da doceria pelotense é resultado de uma intencionalidade incorporada. Como as análises das seções a seguir podem esclarecer, identificamos que essa transmissão tem que ver com a intencionalidade da pessoa praticante e repositório do saber - no caso, a mestra doceira da fábrica de doces pesquisada - sobre o grupo composto por funcionárias e funcionários empregados no empreendimento que ela detém e comanda. Essa intencionalidade escapa à lógica racional da fábrica de doces como empresa capitalista contemporânea e coloca-se a serviço das especificidades da prática doceira, em relação ao seu contexto social, cultural e histórico de produção e reprodução. Entendemos que a tradição é parte do complexo estruturado e estruturante de posições e relações sociais que busca manter a si mesmo através das disposições incorporadas sob a forma do habitus.

\section{A Questão da Transmissão do Conhecimento Prático}

Embora heterogêneos sob o ponto de vista das tradições de pesquisa a que se vinculam, os estudos baseados na prática (practice-based studies) partem do entendimento comum de que ela é uma categoria social e coletiva. Desse entendimento, decorre que o conhecimento é socialmente construído no seio de uma comunidade de praticantes (Brown \& Duguid, 1991) e repousa em práticas sempre situadas e provisórias (Elkjaer, 2004; Gherardi, 2000). Assim, para essa perspectiva teórica, o conhecimento não é visto como residente nas mentes isoladas, mas, sim, como feito pelas pessoas em conjunto, não podendo ser tomado como um recurso cognitivo individual (Cook \& Brown, 1999). 
Conforme Gherardi (2009b, p. 121), "o conhecimento, portanto, não é um ativo que pertence a uma comunidade [ou a certos indivíduos], mas é sim uma atividade - um 'saber' -, que a prática em si constitui ('saber-na-prática')". Como tal, essa forma de conhecimento não pode ser depurada e separada das práticas e transferida de um lugar para outro. Tampouco existe em estado acabado. Em vez disso, o conhecimento dinâmico, caracterizado enquanto saber, saber na prática ou conhecimento prático, está continuamente sendo exercido, reproduzido, refinado e transformado com base em entendimentos tacitamente compartilhados em uma comunidade de praticantes. Por ser relacional e tácito, o conhecimento elaborado através da prática evidencia também um caráter corporal (embodied) e não reflexivo, que tem inspirado estudos sobre a conexão entre saber e aprender na prática e o conhecimento sensível (Strati, 2007) e sobre a compreensão da transmissão, do desenvolvimento e das modalidades de conhecimento prático que se caracterizam enquanto conhecimento incorporado (O'Connor, 2005).

Os estudos baseados na prática endossam as teses de Bourdieu e Polanyi, de que o saber-fazer prático é uma forma de conhecimento pessoal, que existe e se processa no corpo (Gherardi, 2009a, 2009b; Strati, 2007). O conceito de habitus de Bourdieu (1980, 2011) pressupõe o modo como as estruturas sociais são incorporadas pelas pessoas, transformando-as, ao mesmo tempo em que são transformadas por elas. O habitus diz respeito a "disposições duráveis ou capacidades treinadas e propensões estruturadas para pensar, sentir e agir de modos determinados que então as guiam em suas respostas criativas aos constrangimentos e solicitações de seu meio social existente" (Wacquant, 2007, p. 66). O habitus não é um simples condicionamento, resultante das constrições que o meio social apresenta ao indivíduo, porque é, ao mesmo tempo, princípio de ação. É estrutura (disposição durável) e estruturante (geradora de práticas), incorporada por uma comunidade. Por meio do habitus, é possível compreender como as histórias individual e grupal são sedimentadas no corpo, pois o habitus é o produto das experiências biográfica individual e histórica coletiva, além de a interação entre elas (Thiry-Cherques, 2006). O habitus designa uma competência prática, adquirida para e na ação e que resume uma aptidão ou um sentido de se estar perfeitamente ajustado à ordem social por meio de disposições incorporadas que fazem com que os indivíduos dominem as regras do jogo social de que tomam parte.

A ideia de intencionalidade, formulada por Bourdieu (2001), refere-se à indeterminação como a experiência fenomenológica do mundo, meio material, que abarca ou engloba a pessoa. Dessa inclusão, frequentemente despercebida ou recalcada, decorre a incorporação das estruturas sociais sob a forma de estruturas de disposições, de chances objetivas, de antecipações, das quais se adquire um conhecimento e um domínio prático do meio englobante. Da inconsciência de uma consciência surge a intencionalidade, descrita por Bourdieu (2001) de modo bastante simples na frase: "sei confusamente o que depende e o que não depende de mim, o que é 'para mim' ou 'não é para mim' ou 'não para pessoas como eu', o que é razoável para eu fazer, esperar, pedir" (p. 159). O eu, como pessoa que é "sujeito do verbo compreender, não sendo necessariamente um 'sujeito', no sentido da filosofia da consciência, mas sim um habitus, um sistema de disposições” (Bourdieu, 2001, p. 159), encontra-se implicado no espaço em uma relação paradoxal. Afinal, o habitus constitui um agente real, mas constrangido por circunstâncias materiais e culturais às possibilidades limitadas de comportamento, de pensamento e das ações condizentes com certa posição.

Bourdieu $(1996,1997,2001)$ se opõe à ideia de intencionalidade tal como é concebida pela teoria da ação racional e adere à de uma intencionalidade incorporada ou, em outras palavras, de uma intencionalidade inerente ao habitus, que é propriamente o cerne da teoria disposicional da ação. Essa intencionalidade está no jogo da ilusio como "uma maneira de estar no mundo, de estar ocupado pelo mundo fazendo com que o agente possa ser afetado por uma coisa bem distante, ou até ausente, embora participando do jogo no qual está empenhado" (Bourdieu, 2001, p. 165). O corpo sujeito a esse jogo adquiriu um sistema de disposições ajustado às suas regularidades (do jogo) e acha-se "inclinado e apto a antecipá-las praticamente, através de condutas que mobilizam um conhecimento pelo corpo capaz de garantir uma compreensão prática do mundo bastante diferente do ato intencional de decifração consciente que em geral transparece na ideia de compreensão" (Bourdieu, 2001, p. 166). Assim, Bourdieu (2001) propõe que as estruturas cognitivas do agente são produto da incorporação das do mundo no qual ele age. Isso é o mesmo que dizer que o agente nunca é por inteiro o sujeito de suas 
práticas porque as disposições incorporadas do habitus se introduzem até nas intenções aparentemente mais racionais.

A organização social dos saberes engendrados através da prática é a configuração singular do sistema de fatores explicativos que deve ser construída para justificar um estado particular de divisão social de bens e práticas. Desse modo, a homogeneidade das disposições associadas a certas comunidades de praticantes (ou à posição de certos praticantes no interior dessas comunidades) são produto dos mecanismos que fornecem orientação para que esses indivíduos se identifiquem com aquelas práticas, como se estas tivessem sido feitas por eles e para eles. No mesmo sentido, essa configuração singular do sistema de fatores explicativos constitui o princípio de produção das práticas distintivas; "ela representa o estado do sistema das propriedades que transformam a classe em um princípio de explicação e de classificação universal, definindo a posição ocupada em todos os campos possíveis" (Bourdieu, 2011, p. 107).

É certo que essa organização é decorrência do processo irrefletido de institucionalização das práticas e do fato de elas poderem ser caracterizadas como "um modo socialmente reconhecido e relativamente estável no tempo de ordenar itens heterogêneos em um conjunto coerente" (Gherardi, 2006, p. 34). Mas, também, pode-se compreender que a institucionalização, sob a forma de normas a respeito do modo correto ou incorreto de agir conforme a prática (Rouse, 2002) constitui o princípio de produção de práticas distintivas que correspondem ao estado do sistema das propriedades que transformam uma classe em um princípio de explicação (Bourdieu, 2011).

O essencial é que as diferenças nas práticas tornam-se diferenças simbólicas reconhecidas no campo social (Bourdieu, 2011). Em outras palavras, isso significa que a institucionalização das práticas no meio social passa pelo reconhecimento público da propriedade de um dado conhecimento por uma comunidade de praticantes. Mais ainda: que tal reconhecimento é um princípio de distinção, é uma forma de capital e, portanto, de poder. Donde se supõe que as comunidades de praticantes (ou praticantes individuais no interior dessas comunidades) tenham interesse na organização social do conhecimento engendrado através das práticas, na interrupção de seu fluxo contínuo e no estabelecimento de critérios vinculados às disposições do habitus para a acessibilidade e distribuição desses conhecimentos.

O conhecimento prático e seus sistemas de distribuição desempenham um papel na reprodução e no reforço de relações de poder desiguais e possibilitam que certos grupos sociais sejam marginalizados, posto que praticantes em diferentes posições no campo social estão envolvidos continuamente no trabalho de reafirmar, reencenar e transformar para seu proveito estruturas sociais mais amplas nas quais as práticas são forjadas (Clegg, Courpasson, \& Phillips, 2006). Assim, as práticas só podem ser verdadeiramente entendidas se as condições econômicas e sociais de atualização do habitus a que estão relacionadas forem esclarecidas. Isso porque essas condições constituem o princípio dinâmico das práticas (Bourdieu \& Wacquant, 2005).

Tal constatação, evidentemente, não representa uma novidade para os estudos baseados na prática no âmbito dos estudos organizacionais (EOs). Lave e Wanger (1991), por exemplo, já haviam pontuado as dificuldades de se aprender uma prática e, assim, tornar-se um membro (identificado) de uma comunidade de prática, quando as divisões sociais, incluindo as de classe e de gênero, estão estruturadas para impedir ou facilitar o acesso a determinados recursos, formas de atividade, tecnologias, entre outros. Mørk, Hoholm, Ellingsen, Edwin e Aanestad (2010) também abordaram a questão de como as práticas operam efeitos de poder dentro e entre comunidades de praticantes, ao investigarem como comunidades específicas tentaram controlar novas práticas por meio de ações altamente políticas. Contu e Willmot (2003) e Roberts (2006), por sua vez, contemplaram a maneira como a estrutura hierárquica das organizações condiciona as formas de distribuição de saberes. Outros estudos, com foco no posicionamento discursivo, evidenciaram os movimentos políticos de atores em uma rede de relações de poder/conhecimento (Gherardi \& Nicolini, 2002) e o modo como as práticas de compartilhamento do conhecimento são socialmente regulamentadas e incorporadas nas relações de poder/conhecimento (Heizmann, 2011). 
Diante do exposto nesta seção, talvez aquilo que possa se apresentar como contribuição para o campo dos EOs esteja centrado na noção de habitus em relação à ideia de intencionalidade incorporada, em face dessa teorização abrigar a ideia de que as práticas também são elaboradas a partir de componentes incorporados e pré-reflexivos da experiência. Disso decorre que o corpo não é apenas o container do conhecimento encerrado na mente; "o corpo age" (Strati, 2007, p. 62) e os modos de operação e transmissão do conhecimento prático não são orientados por fatores estritamente racionais. Os movimentos, estratégias, decisões políticas e formas de organização que repousam por trás do compartilhamento de saberes práticos estão necessariamente relacionados "à história individual e coletiva dos agentes através dos quais as estruturas de preferência que os habitam são incorporados em uma dialética temporal complexa com as estruturas objetivas que os produziram e que eles tendem a reproduzir" (Bourdieu \& Wacquant, 2005, p. 183).

Conforme assinalado O'Connor (2005), em sua experiência etnográfica na incorporação do saberfazer artesanal característico da cristaleria, a compreensão que um praticante alcança através da prática não é "a síntese intelectual de atos sucessivos por um 'discernimento consciente'; o entendimento que caracteriza o saber-na-prática é uma 'intencionalidade incorporada"” (p. 190). De maneira análoga, defendemos que a transmissão do conhecimento prático - o processo de compartilhar o saber através da prática - também é orientada por uma intencionalidade incorporada. Menos uma escolha racional do que a expressão de significados cujo sentido está ancorado nas experiências corporais, a transmissão do conhecimento prático é "um tipo de coincidência necessária - que tem a aparência de uma harmonia pré-estabelecida" (Bourdieu, 2000, p. 143).

\section{Método}

O topus da nossa investigação é a cidade de Pelotas, Rio Grande do Sul, famosa pela produção artesanal de doces finos, cuja história remete ao século XIX, quando as famílias burguesas de origem portuguesa passaram a recriar receitas tradicionais lusitanas com base nos gostos locais. Especificamente, assumimos como campo de pesquisa uma das mais renomadas fábricas de doces pelotenses, estabelecida, desde 2000, por uma doceira cuja família atua no ramo desde 1955, identificada neste estudo como a mestra doceira. Para justificar a escolha, precisamos esclarecer que a caracterização tradicional, no âmbito da doceria, está relacionada com o caráter exclusivista que a prática logrou ter no contexto em questão. Historicamente, uma comunidade restrita de mulheres praticantes buscou assegurar que a sobranceria sobre algumas receitas fosse uma artimanha de poder. Contemporaneamente, a inserção da doceria de Pelotas no contexto da produção capitalista tem transformado a antiga discrição doceira em segredo comercial. Afinal, à medida que mais e mais pessoas lançam-se em empreendimentos gastronômicos dessa natureza, a maçonaria do doce (Quintas, 2008) em Pelotas, aos poucos, converte-se em uma associação de produtores, fortemente voltada para a proteção do saberfazer tradicional como forma de diferencial competitivo. O caráter exclusivista dessa prática se direciona, então, para a criação de uma espécie de reserva de mercado para as chamadas doceiras tradicionais mulheres que, como a mestra doceira da organização pesquisada, têm reconhecimento público na sociedade pelotense pelo envolvimento com a história da doceria tradicional e que são socialmente autorizadas a desenvolver atividades lucrativas a partir do conhecimento restrito sobre a doceria tradicional.

A fábrica tomada como lócus de estudo é uma das 16 fábricas de doces pelotenses reunidas na Associação dos Produtores de Doces de Pelotas e uma das cinco únicas que têm produção certificada pelo selo de indicação de procedência que garante a origem legítima do doce pelotense e a fidedignidade de sua confecção em relação às receitas originais. A associação tem como missão "proteger o legado das receitas de doces tradicionais" (Associação dos Produtores, n.d.). A conquista do selo de indicação de procedência por algumas fábricas associadas assegura a exclusividade sobre o saber-fazer dos doces, já que o regulamento técnico de produção dos doces tradicionais foi elaborado pelos próprios membros da associação (Associação dos Produtores, n.d.). As cinco fábricas certificadas, entre as quais a fábrica pesquisada, são consagradas localmente como tradicionais em razão, principalmente, do seu tempo de 
fundação e da história de vida (ou, no linguajar êmico, a história no doce) das suas fundadoras. Importa também mencionar que a fábrica pesquisada era a única entre as cinco certificadas que contava com uma especial combinação de fatores, quais fossem: (a) a dona da fábrica era a figura reconhecida publicamente como mestra doceira; e (b) essa pessoa - a dona da fábrica e mestra doceira - continuava trabalhando exclusivamente na confecção dos doces. Assim, justificamos a escolha da fábrica pesquisada pelo fato de a produção desempenhada nela preencher os requisitos teóricos do conceito de habitus relacionado à produção doceira tradicional.

A pesquisa deu-se aos moldes de um estudo etnográfico, em consonância com a proposta de Cavedon (2008) de que o fazer etnográfico pode contribuir para os estudos em administração ao desvelar valores, símbolos e identidades que a pesquisa tradicional de orientação positivista não se propõe a estudar. A escolha desse método ocorreu em razão de certos procedimentos peculiares de pesquisa - notadamente, a observação participante - que permitem ao pesquisador interpretar práticas culturais de um grupo do qual não faz parte. A pesquisa etnográfica foi realizada por uma das autoras deste trabalho (doravante identificada como pesquisadora) e aconteceu entre os meses de fevereiro e julho de 2011. Um primeiro contato com o campo já havia ocorrido em novembro de 2010, quando a pesquisadora viajou a Pelotas pela primeira vez. Àquela época, a pesquisadora não conhecia a cidade, de modo que as primeiras aproximações em relação ao universo da doceria pelotense se deram por intermédio de indicações obtidas junto a comerciários e habitantes locais, contatados ocasionalmente em passeios pelo centro.

Durante a pesquisa, a pesquisadora esteve presente na fábrica de doces em frequência diária, cumprindo expediente de quatro horas nos meses de fevereiro e março e de oito horas nos meses de abril, maio e junho. As impressões sobre as vivências na fábrica foram anotadas em diários de campo, redigidos após cada dia de trabalho na fábrica de doces. Consideramos que a permanência da pesquisadora em campo foi caracterizada por duas fases, as quais correspondem diferentes momentos no cotidiano da doceria e na trajetória de amadurecimento da pesquisa etnográfica. A primeira delas, compreendida entre os meses de fevereiro e abril de 2011, corresponde à entrada em campo e à época de menor produtividade na fábrica, visto que as férias de verão são associadas à redução no consumo de doces na região. As circunstâncias de sazonalidade impediram o engajamento pleno na observação participante, visto que não era possível ocupar o posto de funcionária da fábrica em razão da diminuição da produção.

Nesse primeiro momento, as diferenças entre a pesquisadora e as funcionárias e os funcionários eram evidentes e colocavam-se como obstáculos para a plena inserção no campo. As diferenças repousavam, principalmente, sobre duas questões: a formação acadêmica da pesquisadora e o fato de ela não receber nenhum retorno financeiro sobre o trabalho na fábrica. Isso trouxe à tona incomensurabilidades na ordem dos capitais (Bourdieu, 2007, 2011) que sustentavam as necessidades da pesquisadora e do grupo. Conforme assinala Bourdieu (2011), quando um intelectual se posiciona na situação de um operário sem ter um habitus de operário, ele "aprende a condição operária segundo esquemas de apreciação e percepção diferentes dos esquemas utilizados pelos próprios membros da classe operária para aprender tal condição" (p. 350). Entendemos que não haveria como buscar a alteridade senão por meio de uma "relação ajustada com a condição descrita" (Bourdieu, 2011, p. 350)

Consideramos que as diferenças que se impuseram de maneira marcante entre a pesquisadora e $o$ grupo pesquisado fizeram parte de um rito de passagem no qual a realização da condição ajustada de aceitação que veio a se estabelecer, de fato, no segundo momento da pesquisa, foi precedida por um período de liminaridade (Turner, 1974). Nos meses de maio e junho, quando a produção se intensificou para atender às demandas de um período de acentuado aumento da produção, tornou-se possível experimentar o ponto de vista dos trabalhadores da fábrica e compreender o processo de transmissão do saber-fazer artesanal no interior dessa organização. Foi, então, que a pesquisadora se engajou em atividades consideradas mais importantes, como enrolar e decorar doces, mexer as massas no fogão e até mesmo misturar ingredientes e conhecer a composição das receitas mais tradicionais da doceria. Foi possível transitar entre os setores, manejar os artefatos da cozinha industrial e aprender das funcionárias, funcionários e da própria mestra doceira os requisitos da prática em diferentes funções. Àquela altura, o tempo de convivência havia assegurado que a pesquisadora conquistasse a confiança de parte do grupo e o aval da mestra doceira para explorar todos os setores da fábrica. Nessa assimilação do saber-fazer 
característico de certas etapas do processo produtivo de alguns doces feitos na fábrica, consideramos que a pesquisadora passou a atuar como funcionária da fábrica. Seu status no campo é importante para a análise dos dados, posto que as características corporais e incorporadas que a levaram a ocupar a posição de funcionária têm implicações que serão esclarecidas no decorrer da análise de dados. O mês de julho, que marcou o fim da coleta de dados, foi caracterizado por visitas menos frequentes e de menor duração, que acabaram por se encerrar completamente antes do início do mês de agosto.

Além das vivências propiciadas pela etnografia, a pesquisa também incluiu entrevistas não estruturadas, orientadas por tópicos, quais fossem: (a) a descrição do processo de aprendizagem do saber-fazer doceiro; (b) a descrição das práticas associadas às diferentes funções da doceria; (c) a narrativa da história pessoal e da relação com a cultura da doceria tradicional; e (d) a caracterização da relação da entrevistada ou do entrevistado com a pessoa que transmitiu o saber-fazer doceiro e com os demais colegas de trabalho. Ao orientar a entrevista dessa maneira, buscamos, primeiramente, evocar a reflexão sobre as práticas corporais e fazer com que as entrevistadas e os entrevistados expressassem, através de palavras, os saberes e as práticas que dominam corporalmente (tópicos a e b), bem como revelar os aspectos relacionais e afetivos que pudessem estar imiscuídos no processo de transmitir e incorporar o saber-fazer da doceria (tópicos c e d). Na ocasião da pesquisa, a fábrica contava com 13 funcionárias e dois funcionários, totalizando 15 pessoas, além da mestra doceira, diretamente envolvidas na produção. Ao todo, foram realizadas entrevistas com oito funcionárias, um funcionário e com a mestra doceira. Todas as entrevistas foram registradas em meio digital e posteriormente transcritas para comporem os dados empíricos, juntamente às anotações e aos diários de campo. Convém mencionar que as entrevistas, bem como outras etapas do processo de pesquisa, foram autorizadas pelos participantes e que os responsáveis da empresa autorizaram a divulgação dos resultados. A seguir, apresentamos fragmentos desses materiais, acompanhados das análises que pudemos fazer à luz das teorias que orientam este trabalho.

\section{Incorporação e Transmissão do Saber-Fazer Artesanal dos Doces de Pelotas}

Para apresentar os achados empíricos é necessário esclarecer as relações que conformaram a prática atual e caracterizam seus sistemas de aprendizagem. Também convém evidenciar como cultura e práxis histórica estão relacionadas e como as práticas culturais existentes no presente podem ser relacionadas a outras mais antigas. Isso nos levará a elaborar, nesta seção, uma explanação histórica sobre as mudanças que têm influído na prática doceira tradicional, transformando seu sentido e alterando suas condições de produção e reprodução. Antes de apresentar o processo de transmissão que se constitui enquanto nosso objeto de investigação, precisamos explorar a gênese de dado habitus (Bourdieu, 2011) para daí tornar compreensível o complexo sistema de entrelaçamento de uma prática incorporada com o contexto no qual se desenvolve.

Wacquant (2002, p. 31) propõe que "do mesmo modo como não se poderia compreender o que é uma religião instituída, tal como o catolicismo, sem se estudar em detalhes a estrutura e o funcionamento da organização que a sustenta, no caso, a Igreja Romana", o trabalho de elucidar e esclarecer o sentido de uma prática pressupõe examinar a trama de relações sociais, simbólicas e históricas que se tecem no interior e ao redor dos contextos de produção e reprodução de tal prática. Seguindo essa lógica, não seria possível compreender o significado e as formas de reprodução do saber-fazer do doce na sociedade pelotense contemporânea sem examinar a dinâmica social, histórica e estrutural que fundamenta a existência da fábrica de doces enquanto unidade organizativa.

Surgida a partir da ampliação e sofisticação do equipamento da cozinha doméstica, a fábrica é o espaço no qual a produção familiar vem sendo transformada em empreendimento comercial e onde é possível experimentar corporalmente o conflito tradição/contradição, entre a manutenção bis in idem de práticas tradicionais e as rupturas que caracterizam a dinamicidade de suas significações e que implicam atualizações. Nela, sublinha-se a especificidade da produção doceira enquanto conjunto de ações cuja motivação está ancorada no passado, mas que só pode se projetar no futuro através das práticas 
desenvolvidas no presente. Para além da dimensão física, a fábrica contemporânea é uma forma de organização que explicita a mudança de sentido da prática doceira, desde a motivação para promover a comensalidade até a motivação para auferir renda; desde as relações de produção e consumo tradicionais até as relações de mercado.

A doceria tradicional pelotense está, desde sua origem, vinculada ao habitus originário da aristocracia local, o que coloca o conhecimento embutido nessa prática no centro de um sistema de separações diferenciais que estratifica os indivíduos (e as classes constituídas por eles) por meio dos capitais que possuem e das práticas que reproduzem (Bourdieu, 2011). A tradição dos doces finos origina-se entre as elites luso-brasileiras, vinculadas historicamente aos latifúndios dedicados à pecuária extensiva e à produção de carne de charque, situados na Planície Costeira do Rio Grande do Sul durante o século XIX e início do século XX (Ferreira, Cerqueira, \& Rieth, 2008).

Os critérios de formação do saber-fazer estão intimamente ligados à formação de um gosto (Gherardi, 2009b) - que se manifesta literalmente no paladar - para apreciar as especialidades portuguesas, feitas com ovos, trigo e açúcar. Herdeiras da culinária portuguesa, foram as mulheres das famílias mais abastadas da cidade de Pelotas que reinventaram as receitas tipicamente lusitanas, num intercâmbio alimentar que transformou os sabores da cultura ibérica, ao mesmo tempo se mantendo fiel aos seus ingredientes básicos e aos princípios sociais relacionados à sua prática. Nesse contexto, a doceria se conformou mola mestra de uma forma de sociabilidade, já que era, originalmente, prática supérflua, voltada para a distração e o convívio social de suas praticantes.

A gênese de dado habitus doceiro está relacionada ao que Freyre (2006) chama de açucarocracia e que surge nas diferentes localidades do Brasil onde "a arte do doce teria alguma coisa de "princípio social" (Freyre, 2012, p. 31). A origem comum dessas docerias típicas é a sociedade patriarcal, latifundiária e escravocrata que aqui instituiu o colonizador português. Sendo assim, embora a tradição doceira de Pelotas remeta a uma ancestralidade portuguesa cultivada entre a aristocracia local, são frequentes os relatos da participação da mão de obra negra na elaboração dos quitutes. A pujança econômica que caracterizou o ciclo do charque na Pelotas no século XIX deve-se, afinal, ao emprego de escravos na pecuária e produção dos seus derivados (Ferreira \& Cerqueira, 2012).

A presença de mulheres negras nas casas brasileiras do período escravocrata e posteriormente, como demonstra nossa história social, indica a influência de culturas africanas no nosso cotidiano. Conforme aponta Freyre (1975), essa influência abrange um amplo espectro de práticas, que vão desde os saberes relacionados à culinária, ao cuidado infantil e à manutenção dos serviços domésticos de limpeza até relações afetivas e mesmo sexuais que fundaram certa plasticidade no contato entre os descendentes de africanos e portugueses no Brasil. Plasticidade essa que se traduz em manifestações culturais das mais diversas, como a doceria tradicional de Pelotas, que atesta a importância desse contato para a formação social do habitus vinculado à prática em questão. Através dessa questão étnica, que se articula com a de gênero - ambas desenvolvendo-se no interior do sistema patriarcal, produtor de assimetrias de poder - temos, então, os primeiros subsídios para compreender a intencionalidade incorporada que pode se observar contemporaneamente no processo de transmissão do saber-fazer doceiro.

A partir das primeiras décadas do século XX, uma primeira geração de mulheres passou a utilizarse, de maneira profissional e com vistas ao provimento da economia doméstica, dos saberes até então aplicados nas cozinhas dos casarões (Ferreira et al., 2008). Desse movimento decorre o início do processo de profissionalização da atividade doceira. A partir da interpretação de que o saber-fazer doceiro é uma forma de capital, podemos compreender que a ampliação da escala e dos objetivos de produção concorreu para a abertura das possibilidades de distribuição de poder no contexto em questão.

Mencionamos na seção anterior que a doceria tradicional de Pelotas tem sido alvo de combinados esforços de salvaguarda que visam manter a prática circunscrita a certos limites físicos (propriamente, as fronteiras da cidade de Pelotas, através do Certificado de Origem) e a certa comunidade de praticantes (as herdeiras putativas dessa tradição, reconhecidas também pela certificação de origem para os doces tradicionais pelotenses). Essas medidas são importantes porque estimulam a celebração das tradições 
locais, a proteção do saber-fazer imanente à cultura da cidade e a permanência da doceria artesanal em um contexto fortemente caracterizado pela mecanização dos processos produtivos. Todavia, desenvolvem-se ao redor de um sentido de forte apropriação particular dessa prática, corroborando o contexto original exclusivista, restrito a pessoas iniciadas, reconhecidas por certas insígnias corporais de pertencimento ao habitus associado à doceria.

\section{A Transmissão do Saber-Fazer dos Doces de Pelotas Enquanto Intencionalidade Incorporada}

Agora que esclarecemos o contexto original da doceria pelotense e informamos os subsídios históricos da compreensão do habitus associado a essa prática cultural, podemos partir para a análise dos dados empíricos. No campo, vimos que, muito embora a mestra doceira afirme conscientemente a apriorística igualdade de condições entre as funcionárias e os funcionários da fábrica de doces, nem todas as pessoas têm iguais condições de conhecer as receitas e os procedimentos de feitio dos doces e incorporar, na prática, o saber-fazer da doceria. Ou seja, nem todas as pessoas são alvo do processo de transmissão desse conhecimento específico. $O$ fato merece atenção porque a intenção incorporada, objeto dessa análise, faz com que todas as ações tenham uma coerência em relação às disposições do habitus (Bourdieu, 2001). Entendemos que a interdição de acesso ao saber-fazer doceiro, imposta a algumas pessoas, reflete estruturas de poder historicamente condicionadas. Convém agora esclarecê-las.

No cenário em que a doceria artesanal tradicionalmente vinculada ao habitus da aristocracia lusobrasileira tornou-se um empreendimento comercial independente das condições originais de transmissão do saber-fazer inerente a essa prática cultural, o treinamento de mão de obra especializada passou a ser um problema. Na fábrica onde a pesquisa teve lugar, a alta rotatividade de funcionários é consoante com as queixas da mestra doceira sobre as dificuldades de encontrar pessoas esforçadas e interessadas para aprender os processos de produção dos doces pelotenses. Essas queixas carecem de uma análise mais acurada para que se desvende a intencionalidade subjacente às ações que perfazem a distribuição do conhecimento típico da doceria.

Durante o período de permanência em campo foi possível perceber divergência entre a visão da mestra doceira a respeito da vontade de aprender e dedicação ao trabalho de seus funcionários e, mais especificamente, de suas funcionárias. O esforço e o interesse em aprender, proclamados pela mestra doceira como insuficientes entre as funcionárias, eram expressados pela maioria delas quando perguntadas em entrevista quais seriam as características fundamentais para aprender e fazer bem os doces produzidos na fábrica. Ou seja, a divergência que se observou diz respeito às opiniões da mestra doceira e das funcionárias sobre o trabalho desempenhado por essas últimas na fábrica de doces. Para a mestra doceira, as funcionárias não eram dedicadas e esforçadas o suficiente. As funcionárias, no entanto, consideravam que esforço e interesse eram necessários para aprender e fazer bem as tarefas da doceria e aquelas que buscavam realizar um bom trabalho podiam se considerar portadoras dessas características.

A própria pesquisadora tinha o objetivo de desvendar os processos de incorporação do saber-fazer artesanal - o que, na condição da observação participante, implicava a assimilação de pelo menos alguma parte do amplo conjunto de saberes que estão por trás da prática da doceria. As experiências de campo no dia a dia compartilhado com as funcionárias também revelavam diferentes situações em que a vontade de aprender era demonstrada sob a forma de satisfação diante do sucesso na realização de alguma tarefa nova ou do prazer que a maioria delas dizia sentir ao apreciar o resultado final do seu trabalho.

Ao longo do período de permanência na fábrica, a assistência da mestra doceira à pesquisadora ocorreu frequentemente, mas o que se pôde perceber foi que as etapas da produção que se apresentavam como obstáculos para a assimilação do processo completo de feitio de uma receita eram expostas por ela de um modo sempre oblíquo e esquivo, através de demonstrações rápidas demais para serem plenamente entendidas ou de descrições demasiadamente lacônicas. Por se tratar de uma forma de saber 
tácito, as demonstrações da mestra doceira davam-se pela execução da tarefa uma ou duas vezes e pela produção de um modelo que serviria de guia para a pesquisadora (e demais funcionárias novatas, como foi possível observar). As sensações experimentadas nesse universo delimitado evidenciavam a incorporação dos saberes como algo a ser efetivado na repetição diária.

O método indicava que as orientações da mestra doceira seriam suficientes para que os aprendizes elaborassem suas próprias maneiras de fazer, conquanto atendessem às especificações contidas na demonstração inicial e que se assemelhassem ao modelo. Nesse ponto, a pesquisadora podia supor que a incorporação do saber-fazer dava-se através de descobertas perceptivas que envolviam a experimentação das matérias primas e do contato com o modelo. Talvez por isso não houvesse na fábrica nenhum tipo de manual ou livro contendo informações sobre a composição de cada receita, tampouco instruções práticas sobre como os doces deveriam ser produzidos.

A pesquisadora percebeu, ainda, que funcionárias que ingressavam na fábrica eram admitidas para desempenhar alguma função bastante específica. Sendo assim, durante o tempo da pesquisa, uma novata foi contratada para preparar os bem-casados, enquanto outra se ocupava apenas de misturar os ingredientes e dar o ponto nas massas de ovos e camafeus. Praticamente todas desempenhavam funções bastante limitadas e, justamente por isso, não tinham a possibilidade de assimilar nada muito além das especificações do seu trabalho, visto que isso poderia implicar exercer a função de outra colega.

O sistema de divisão do trabalho e a configuração do espaço da fábrica contribuíam para essa limitação. Foi possível perceber que as funcionárias se especializavam na produção de apenas um ou dois doces e apresentavam dificuldade em descrever os processos necessários para a elaboração das receitas que não estavam sob sua responsabilidade. Algumas delas apresentavam limitação mesmo em descrever completamente o processo de produção dos doces sob sua responsabilidade. Depois de certo tempo de inserção em campo, a pesquisadora pôde perceber que nenhuma receita the foi integralmente transmitida pela mestra doceira.

No campo, as funcionárias demonstravam muito respeito aos limites entre funções, o que era expresso, por exemplo, pela posse que acreditavam ter sobre o espaço destinado aos doces que elas produziam. Era comum ouvi-las se referir ao setor o qual trabalhavam como sua própria cozinha ou sua própria bancada e aos instrumentos de trabalho existentes nesses espaços como sua pia ou seu forno. Havia, portanto, uma apropriação territorial do espaço físico da fábrica em razão do layout concebido para os fluxos e processos de produção e a posição que cada funcionária ocupava neles.

Entre todos os funcionários da fábrica, apenas os dois homens circulavam livremente por todos os espaços e demonstravam conhecimento sobre a elaboração da maioria das receitas. Conforme observação da pesquisadora, essas duas pessoas recebiam atenção diferenciada por parte da mestra doceira e eram autorizadas a acompanhá-la ao longo de sua permanência na fábrica. Um deles, especialmente, parecia ocupar, no momento da pesquisa, a posição de aprendiz, que havia sido anteriormente ocupada pelo outro, conforme se constatou. Além de serem os dois únicos homens a trabalharem na produção, ambos tinham características em comum, que puderam ser interpretadas como semelhanças que os aproximavam. Ambos eram negros (além deles, havia apenas uma funcionária negra na fábrica), ingressaram no espaço de trabalho ainda muito jovens (um aos 17 e o outro aos 20 anos) e em condições excepcionais, visto que não se candidataram aos postos de trabalho que ocupavam, tendo sido convidados a assumi-los.

Todas as funcionárias empregadas na fábrica onde a pesquisa teve lugar haviam exercido anteriormente atividades ligadas aos trabalhos domésticos, seja como empregadas domésticas, cozinheiras ou cuidadoras de crianças, ou haviam sido funcionárias de outras fábricas de produção de doces artesanais. Os dois funcionários, por seu turno, desempenhavam atividades ligadas ao universo masculino, considerando-se a tradicional divisão sexual do trabalho: o primeiro a ser contratado estivera trabalhando como auxiliar de pedreiro em serviço de reparos na estrutura da fábrica quando foi convidado a entrar na fábrica e aprender a fazer doces; o segundo ingressou no ambiente da doceria, que se localiza em um sítio, após uma temporada atuando como tratador de cavalos no galpão próximo à fábrica. 
Segundo a mestra doceira, esses dois funcionários eram os mais dedicados e esforçados e, portanto, mais capazes de assimilar os saberes relacionados à prática da doceria. Os homens, por seu turno, frequentemente confessavam seu respeito e admiração pela mestra doceira e atribuíam a ela a oportunidade de mudar de vida. Expressavam, então, uma gratidão que parecia estabelecer um vínculo profundo de lealdade que os levava a dizer que só sairiam da fábrica quando fossem mandados embora, o que não acontecia com as funcionárias, entre as quais se observava o desejo de buscar oportunidades melhores em outros lugares. Os funcionários homens também entendiam que os conhecimentos adquiridos no trabalho ao lado da mestra doceira eram uma profissão que poderia lhes garantir autonomia de trabalho e independência financeira. Se os homens percebiam seu trabalho enquanto um ofício, assim como a mestra doceira, as funcionárias percebiam-no apenas como um emprego, o que possivelmente implica posturas diferentes e justifica, de certa forma, a percepção da mestra doceira de que elas eram pouco esforçadas e desinteressadas. Conforme essa análise, o significado elaborado para o trabalho das funcionárias no cotidiano da fábrica de doces levava ao pouco esforço e desinteresse que impediam a incorporação da prática em questão, conforme o entendimento da mestra doceira. As funcionárias, inicialmente estimuladas a aprender, eram levadas, pelas condições a elas impostas, a adotarem postura contrária ao aprendizado. Percebe-se, na situação, como o indivíduo, enquanto agente, tem participação ativa na reprodução da ordem social e como, apesar disso, as práticas podem ser retificadas enquanto entidades que pairam sobre as motivações dos indivíduos, posto que estas nunca podem ir muito além das chances que a estrutura objetiva oferece a eles.

A partir dessa situação, podemos compreender que a dimensão da contradição (Lave \& Wangler, 1991) na tensão entre velhos e novos praticantes na reprodução de uma comunidade de práticas é consequência de uma intencionalidade incorporada que orienta os processos de transmissão para a lógica cultural incorporada, e não para a lógica funcional que busca eliminar a incoerência entre a lógica racional orientadora das práticas e seu resultado esperado. Isso porque as consequências dos obstáculos impostos à aprendizagem das funcionárias recaíam sobre a qualidade e o volume da produção da fábrica e afetavam o resultado da doceria, nesse caso entendida enquanto empresa com objetivos econômicos.

Por outro lado, se pensarmos na doceria enquanto prática tradicional, os objetivos organizacionais não se reduzem a interesses hiper-racionalistas, mas são explicados como intencionalidade, enquanto condição fundamental da interação que caracteriza as práticas. Os agentes e as relações que estabelecem não podem ser identificados na dualidade estrutura/agência, mas sim como duas faces do mesmo fenômeno que origina, propriamente, o espaço social enquanto malha de interações (Schatzki, 2006).

A partir das relações diferenciadas que se estabeleceram entre a mestra doceira e seus funcionários, percebemos que o processo de transmissão do saber-fazer característico da doceria pelotense está condicionado a certa intencionalidade incorporada, associada a questões de gênero, etnia e trajetória de vida. Parece-nos, afinal, que tomar os funcionários homens e negros por aprendizes não foi uma escolha racional da mestra doceira, que jamais conseguiu expressar em termos lógicos o porquê de julgar as funcionárias, de modo geral, desinteressadas e incapazes de aprender.

O fato de os funcionários homens/negros receberem um tipo diferenciado de tratamento por parte da mestra doceira e dessa diferença se notar, sobretudo, no sucesso maior da transmissão do saber-fazer incorporado para essas pessoas denota uma escolha orientada por determinadas características incorporadas que remetem ao contexto simbólico de produção e reprodução da prática em questão. A etnia parece-nos a mais evidente dessas características, visto que a tradição doceira está atrelada à influência de mulheres afrodescendentes sobre essa prática, o que concorre para a consolidação e a perpetuação desse saber-fazer nas condições originais de transmissão. Corrobora-se, assim, a ideia de que as contribuições africanas estão na base de muitas das práticas alimentares características da cultura brasileira (Freyre, 1975).

Como havia outra funcionária negra na fábrica, podíamos supor que não existia, por parte da mestra doceira, nenhuma restrição direta à admissão de funcionárias negras e que pessoas com essas características (gênero e etnia) poderiam ingressar na fábrica e ocupar a posição de aprendizes. Todavia, a combinação delas é que se colocou como uma questão interessante em nossas análises de dados de campo. Isso porque a relação entre etnicidade e gênero no contexto da fábrica pesquisada se dá de modo 
diferente do que podia ser observado nos sistemas tradicionais de transmissão da habilidade. Antes, havia uma restrição dos homens ao espaço da cozinha, visto que essa e outras práticas domésticas cabiam às mulheres dada a divisão sexual do trabalho que se observava. Mas, com a complexificação das relações entre classes sociais e gênero, a partir da entrada das mulheres no mercado de trabalho e da mudança na organização de alguns tipos de trabalho doméstico, como a profissionalização da culinária, a clássica divisão do trabalho se modificou (Arán, 2003).

Postos de trabalho relacionados às práticas de reprodução da vida doméstica, como a culinária, passaram a ser exercidas também por homens e observa-se, no interior dessa moderna reformulação dos papéis de gênero no trabalho, a reprodução das diferenças entre o trabalho masculino e o feminino. Barbosa (2012) pontua que a gastronomia praticada por cozinheiros homens tende a ser percebida como uma atividade profissional - representada através da figura do chef de cozinha - enquanto a gastronomia feminina tende a ser percebida como uma atividade menos formal e qualificada. Possivelmente, essas questões relacionadas às identidades de gênero e trabalho estão incorporadas nas relações que a mestra doceira estabelece com funcionárias e funcionários, no campo de pesquisa. Donde concluímos que, apesar de o saber-fazer da doceria estar associado tradicionalmente ao trabalho feminino, o exercício público e profissional dessa atividade insere-a em novas elaborações simbólicas associadas ao trabalho masculino.

Também não se pode excluir dessa análise a questão do poder imbricado na combinação das relações de gênero, etnicidade e classe social, que impõe outras nuanças a essas ordens identitárias. A mestra doceira, enquanto herdeira das tradições das famílias mais ricas da cidade de Pelotas, distinguese das funcionárias em razão de uma diferença de classe social. Ainda que a mestra e a funcionária se aproximem conforme critérios identitários de gênero e etnia (são todas mulheres e apenas uma entre as 13 funcionárias é negra), a classe social se impõe como uma barreira para a aproximação entre elas. Já no caso dos funcionários, embora a diferença de classe também existisse, o fato de serem homens parecia conferir a eles status superior, resultado da assimetria de poder entre homens e mulheres na sociedade como um todo. No contexto da fábrica, a combinação das características incorporadas gênero e classe condicionam a acessibilidade aos saberes engendrados na prática e sua distribuição conforme a organização social do poder. Essa organização é a condição objetivamente observável da relação entre práticas doceiras e contexto; é a síntese das práticas realizadas em um campo dotado de certa lógica, segundo a fórmula [(habitus) (capital)] + campo = prática (Bourdieu, 2011).

No que diz respeito à transmissão desse saber-fazer como fruto de uma intencionalidade incorporada, as restrições que a mestra doceira impõe à assimilação de saberes por parte das funcionárias estão relacionadas à manutenção das estruturas de poder de classe, que diferenciam a experiência de gênero. Ao negar o acesso ao conhecimento às funcionárias, a mestra doceira impedia que elas se engajassem em um ofício que lhes permitisse autonomia profissional. Esse fato evidencia que "poder e sexualidade estão entrelaçados" (Calás \& Smircich, 2006, p. 292) e que as relações de poder que emanam das diferenças de classe social se reproduzem também entre as mulheres (Millet, 2000; Parker, 1984).

A condição de se tornar alvo da transmissão do saber-fazer doceiro parecia reservada mais aos homens do que às mulheres, e foi neles que notamos o processo mais espontâneo de desenvolvimento da habilidade característica do saber-fazer prático da doceria. Tal atitude se coaduna com o discurso da incorporação do saber-fazer como princípio de uma mudança de vida. Apesar disso, convém pontuar que as pessoas que ocupavam os postos de aprendizes e estavam em vias de alcançar a condição vivencial de mestres no ofício da doceria acumulavam, em seus corpos, características que atuavam como marcas negativas no que diz respeito ao desenvolvimento de projetos empreendedores que pudessem surgir a partir do conhecimento prático.

Os dois homens tinham experimentado contextos familiares e educacionais irregulares, o que lhes privava de características tidas como favoráveis ao empreendedorismo (à livre-iniciativa e à autodeterminação). Embora eles experimentassem, no interior da fábrica, um ambiente aberto à experiência criadora, pois estavam sendo levados a dominar os processos de trabalho na sua integralidade, a conhecer as peculiaridades do saber-fazer doceiro e a empreender esforços no sentido 
de descobrir os significados da doceria e reelaborá-los, eles pareciam ser incapazes de desenvolver projetos empreendedores para além desses limites.

$\mathrm{Na}$ esteira desse argumento, um segundo aspecto relacionado à intencionalidade incorporada dirige-se à definição do referido grupo específico como um tipo de personalidade ou de disposições de comportamento que atendem às demandas objetivas para que os indivíduos possam ser inseridos na dinâmica da mobilidade social e que tenham a possibilidade de, efetivamente, mudar de vida e de escapar de uma anterior situação subalterna. Ainda que os funcionários homens tivessem acesso ao conhecimento prático da doceria, eles não eram considerados capazes de empreender e fundar estabelecimentos comerciais que fizessem concorrência ao negócio da mestra doceira em questão ou aos outros negócios no ramo da doceria pelotense. Assim, percebemos que mesmo quando o saber-fazer foi compartilhado, isso se deu de modo a não ameaçar a posição social dos tradicionais herdeiros desse valioso legado.

Importa dizer, a respeito disso, que os mecanismos de preservação do saber-fazer doceiro descritos anteriormente visam defender a prática tradicional através de ações desenvolvidas por pessoas que agem a partir de motivações e estratégias referidas a sistemas de forças sociais (Bourdieu, 2011). Cabe indagar, portanto, "qual é o objeto dessa prática, quais são os sujeitos que a põem em marcha, em que condições e quadro institucional isso ocorre, e que valores ela, por sua vez, mobiliza" (Arantes, 2006, p. 426). O apelo contemporâneo ao empreendedorismo através da doceria, embora possa revestir a prática de uma aura de modernização, continua fundamentalmente vinculado ao contexto original de sua produção e reprodução que, por sua vez, insere-se no contexto mais amplo de produção e reprodução das diferenças de poder entre pessoas na estrutura social. O fenômeno da desigualdade não está, assim, associado a qualquer forma de personalismo, mas à impessoalidade de mecanismos pré-reflexivos que se alimentam de uma neutralidade aparente. Mesmo que os funcionários homens sejam detentores de maior poder no contexto da fábrica de doces, eles se igualam às mulheres na impossibilidade de adaptação às relações econômicas e sociais de ascensão.

A situação analisada dá conta, então, de dois aspectos imbricados na intencionalidade incorporada que determina a transmissão do saber-fazer doceiro apenas para algumas pessoas. O primeiro deles é que a lógica pré-reflexiva orientadora desse processo, no âmbito da fábrica de doces, busca a preservação do conhecimento da doceria em condições o mais possível aproximadas às condições originais de sua produção e reprodução. Mecanismos corporais e incorporados assinalam os caminhos de sua atualização, no espectro das possibilidades gestadas historicamente. São especificidades culturais, mais do que necessidade consciente, que conduzem a mestra doceira na escolha de seus aprendizes. Essas especificidades dão conta de estruturas de poder e dominação, que caracterizam o contexto da doceria como universo simbólico com dimensão histórica, no qual a razão para os fatos paira acima dos determinantes econômicos, sociais e políticos sincrônicos à contemporaneidade. Ainda que atualmente a expansão do negócio esteja ameaçada pela falta de praticantes qualificados, nos termos descritos pela mestra doceira e evidenciados ao longo desta análise, distribuir o conhecimento da doceria entre pes soas diversas significa compartilhar um poder que tem de ser reservado privilégio de um grupo específico.

Em suma, buscamos expor através da análise dos dados de campo empreendida nesta seção: a intencionalidade incorporada que orienta o processo de transmissão do saber-fazer doceiro na fábrica de doces tem como lógica subjacente a manutenção das relações de poder na estrutura social. Relações essas que têm se reproduzido irrefletidamente como tradição, como nexos de sentido historicamente elaborados no âmbito da cultura e que dão conta de uma forma naturalizada de reprodução das desigualdades. Por mais consciente que a mestra doceira estivesse, nos termos de uma racionalidade instrumental, sobre a necessidade de perpetuar o saber-fazer doceiro, as disposições incorporadas no habitus dessa tradição a impediam de perceber como sua relação com as funcionárias e funcionários da fábrica perpetuava desigualdades. Pessoalmente, ela não fomentava preconceitos, nem buscava agravar as condições de vida daquelas e daqueles que empregava. Mas o fato de sua existência estar condicionada a um contexto sociocultural no qual as desigualdades são necessárias a impelia a preservar suas condições de reprodução. A organização que ela comandava e a que personificava em grande medida obedecia a essa mesma tendência, a qual se mostrava também coerente com os rumos que o setor doceiro de Pelotas vinha tomando, no momento em que a pesquisa foi realizada. 


\section{Considerações Finais}

Com o objetivo de mostrar como a transmissão de um conhecimento prático é fruto de uma intencionalidade incorporada, refletimos neste artigo sobre a problemática dos processos de aprendizagem organizacional no âmbito de uma comunidade de prática. Por meio de pesquisa etnográfica, identificamos que os processos de transmissão de um saber-fazer artesanal, tal como a prática doceira pesquisada, não se dão aos moldes de uma aquisição, mas de uma inculcação, resultante de um engajamento corporal que transforma o indivíduo por meio da performance prática. A partir daí, buscamos compreender como esse conhecimento incorporado seria transmitido - o que nos conduziu a tomar o conceito de habitus como referência teórica. Ao recuperarmos as origens históricas da prática pesquisada - a doceria tradicional de Pelotas - tentamos compreender de que maneira o contexto social, material e histórico de sua origem oferece as estruturas e os mecanismos estruturantes para a formação de uma comunidade de praticantes, em que cada membro, individualmente, compartilhe profundamente das características que lhes são inoculadas no próprio exercício da prática.

Teoricamente, buscamos contribuir para o estudo das práticas organizacionais, no campo dos EOs brasileiros, com uma abordagem que se baseou em uma compreensão aprofundada do contexto para explicar a questão da produção/reprodução das práticas através de processos de transmissão de conhecimento prático. Essa abordagem pode contribuir para os EOs e, especialmente, para o conjunto de estudos baseados na prática (Gherardi, 2009b) e para os estudos sobre aprendizagem situada (Contu \& Willmot, 2003). Com o conceito de intencionalidade incorporada, ressaltamos uma forma de compreensão da relação corpo, contexto e prática, tentando evidenciar como características corporais e incorporadas orientam expressões de significados que corroboram, por meio das práticas organizacionais, a ordem social estabelecida.

A pesquisa demonstrou que, muito embora a prática em questão oriente um sistema produtivo relativamente simples, o fato de a maior parte das pessoas envolvidas não deter o domínio pleno sobre o saber-fazer que a orienta indica que as relações de transmissão de um saber incorporado envolvem questões mais complexas do que a disposição ou o interesse para ensinar ou aprender uma prática. Acreditamos que esse achado, que chama atenção para aspectos históricos e contextuais das práticas como condicionantes (no sentido estrutural) do processo de transmissão de conhecimento, pode também ser considerado válido em relação a outros estudos que almejem analisar as práticas de organizações diferentes da que estudamos, como organizações não artesanais e de maior porte.

Mesmo que o conhecimento prático relacionado a características distintas de organização e arranjos de trabalho possa ser considerado mais impessoal e, nesse sentido, menos incorporado, argumentamos que a cultura e as circunstâncias sociais e históricas do ambiente circundante interferem até mesmo na vivência de práticas formais e fortemente institucionalizadas, conforme podem atestar os estudos interpretativos sobre cultura organizacional (Cavedon \& Fachin, 2002; Martin \& Frost, 2001). De modo geral, para organizações de diferentes tipos, as práticas são um ponto de partida interessante para compreender os sentidos incorporados e manifestos através do corpo, porque analisar as práticas envolve descobrir princípios que justificam e explicam ações. Tal perspectiva permite que se observem as diferenças que surgem nas relações entre pessoas a partir de aspectos situacionais e dinâmicos, mas também ancorados na cultura e, consequentemente, na história pacífica ou conflituosa desses contatos.

\section{Referências}

Arán, M. (2003). Os destinos da diferença sexual na cultura contemporânea. Revista de Estudos Feministas, 11(2) 339-422. https://periodicos.ufsc.br/index.php/ref/article/view/9839. 026X2003000200004 
Arantes, A. (2006). O patrimônio cultural e seus usos: a dimensão urbana. Habitus, 4(1) 425-435.

Associação dos Produtores de Doces de Pelotas. (n.d.). Associação. Recuperado de http://www.docesdepelotas.org.br/Associacao

Barbosa, L. (2012). Os donos e as donas da cozinha. In M. E. Freitas \& M. Dantas (Orgs.), Diversidade sexual e trabalho (pp. 171-202). São Paulo: Cenage Learning.

Bosi, E. (1987). Memória e sociedade: lembranças de velhos. São Paulo: Queiroz e EDUSP.

Bourdieu, P. (1980). Esboço de uma teoria da prática. Lisboa: Celta.

Bourdieu, P. (1996). Razões práticas: sobre a teoria da ação. Campinas: Papirus.

Bourdieu, P. (1997). Esboço de uma teoria da prática: precedido de três estudos de etnologia cabila. Oieiras: Celta.

Bourdieu, P. (2000). Pascalian meditations. Stanford: Stanford University Press.

Bourdieu, P. (2001). Meditações pascalianas. Rio de Janeiro: Bertrand Brasil.

Bourdieu, P. (2007). O poder simbólico. Rio de Janeiro: Bertrand Brasil.

Bourdieu, P. (2011). A distinção: crítica social do julgamento. Porto Alegre: Zouk.

Bourdieu, P., \& Wacquant, L. (2005). Una invitación a la sociologia reflexive. Buenos Aires: Siglo Ventiuno Editores.

Brown, J. S., \& Duguid, P. (1991). Organizational learning and communities-of-practice: toward a united view of working, learning, and innovation. Organization Science, 2(1), 40-57. Retrieved from http://dx.doi.org/10.1287/orsc.2.1.40. doi: 10.1287/orsc.2.1.40

Brown, J. S., \& Duguid, P. (2001). Knowledge and organization: a social-practice perspective. Organization science, 12(2), 198-213. doi: 10.1287/orsc.12.2.198.10116

Calás, M. B., \& Smircich, L. (2006). Do ponto de vista da mulher: abordagens feministas em estudos organizacionais. In S. R. Clegg, C. Hardy, \& W. R. Nord (Eds.), Handbook de estudos organizacionais: modelos de análise e novas questões em estudos organizacionais (Vol. 1, pp. 273-327). São Paulo: Atlas.

Cavedon, N. R. (2008). Antropologia para administradores. Porto Alegre: UFRGS.

Cavedon, N. R., \& Fachim, R. C. (2002). Homogeneidade versus heterogeneidade cultural: um estudo em universidade pública. Organização e Sociedade, 9(25) 61-76. doi: 10.1590/S198492302002000300003

Clegg, S., Courpasson, D., \& Phillips, N. (2006). Power and organizations. London: Sage.

Contu, A., \& Willmot, H. (2003). Re-embedding situatedness: the importance of power relations in learning theory. Organization Science, 14(3), 283-296. Retrieved from http://dx.doi.org/10.1287/orsc.14.3.283.15167. doi: 10.1287/orsc.14.3.283.15167

Cook, S. N., \& Brown, J. S. (1999). Bridging epistemologies: the generative dance between organizational knowledge and organizational knowing. Organization Science, 10(4) 381-400. Retrieved from http://dx.doi.org/10.1287/orsc.10.4.381. doi: 10.1287/orsc.10.4.381

Elkjaer, B. (2004). Organizational learning: the "third way". Management Learning, 35(4), 419-434. doi: $10.1177 / 1350507604048271$ 
Ferreira, M. L., \& Cerqueira, F. (2012). Mulheres e doces: o saber-fazer na cidade de Pelotas. Patrimônio $\quad e \quad$ Memória, 8(1), 255-276. Recuperado de http://pem.assis.unesp.br/index.php/pem/article/view/156

Ferreira, M. L., Cerqueira, F. V., \& Rieth, F. M. S. (2008). O doce pelotense como patrimônio imaterial: o diálogo entre o tradicional e a inovação. Métis: História e Cultura, 7(13), 91-113. Recuperado de http://www.ucs.br/etc/revistas/index.php/metis/article/viewFile/696/502

Freyre, G. (1975). Casa grande e senzala. Rio de Janeiro: José Olímpio.

Freyre, G. (2006). Sobrados e mucambos: decadência do patriarcado rural e desenvolvimento do urbano. São Paulo: Global.

Freyre, G. (2012). Açúcar: uma sociologia do doce, com receitas de bolos e doces do Nordeste do Brasil. São Paulo: Global.

Gherardi, S. (2000). Practice-based theorizing on learning and knowing in organizations. Organization, 7(2), 211-223. doi: 10.1177/135050840072001

Gherardi, S. (2006). Organizational knowledge: the texture of workplace learning. Malden: Blackwell.

Gherardi, S. (2009a). Introduction: the critical power of the practice lens. Management Learning, 40(2), 115-128. doi: 10.1177/1350507608101225

Gherardi, S. (2009b). Practice? It's a matter of taste. Management Learning, 40(5), 535-550. doi: $10.1177 / 1350507609340812$

Gherardi, S., \& Nicolini, D. (2002). Learning in a constellation of interconnected practices: canon or dissonance? Journal of Management Studies, 39(4), 419-436. doi: 10.1111/1467-6486.t01-100298

Gherardi, S., \& Nicolini, D. (2003). To transfer is to transform the circulation of safety knowledge. Organization, 7(2), 329-348. doi: 10.1177/135050840072008

Gomez, M. L., Bouty, I., \& Drucker-Godard, C. (2003). Developing knowing in practice: behind the scenes of haute cuisine. In D. Nicolini, S. Gherardi, \& D. Yanow (Eds.), Knowing in organizations: a practice-based approach (pp. 100-125). Armonk: M. E. Sharpe.

Heizmann, H. (2011). Knowledge sharing in a dispersed network of HR practice: zooming in on power/knowledge struggles. Management Learning, 42(4), 379-393. Retrieved from http://mlq.sagepub.com/content/42/4/379.short. doi: 10.1177/1350507610394409

Lave, J., \& Wenger, E. (1991). Situated learning: legitimate peripheral participation. Cambridge: Cambridge University Press.

Martin, J., \& Frost, P. (2001). Jogos de guerra da cultura organizacional: a luta pelo domínio intelectual. In S. R. Clegg, C. Hardy, \& W. R. Nord (Orgs.), Handbook de estudos organizacionais (Vol 2, pp. 219-251). São Paulo: Atlas.

Merleau-Ponty, M. (2005). Fenomenologia da percepção. Rio de Janeiro: Martins Fontes.

Millet, K. (2000). Sexual politics. New York: Doubleday \& Co.

Mørk, B. E., Hoholm, T., Ellingsen, G., Edwin, B., \& Aanestad, M. (2010). Challenging expertise: on power relations within and across communities of practice in medical innovation. Management Learning, 41(5), 575-592. doi: 10.1177/1350507610374552

Nicolini, D., Gherardi, S., \& Yanow, D. (Eds.). (2003). Knowing in organizations: a practice-based approach. New York: ME Sharpe. 
O'Connor, E. (2005). Embodied knowledge: the experience of meaning and the struggle towards proficiency in glass blowing. Ethnography, 6(2), 183-204. doi: 10.1177/1466138105057551

Parker, R. (1984). The subversive stitch: embroidery and the making of the feminine ideal. London: The Women's Press.

Quintas, F. (2008). A saga do açúcar. Recife: FUNDAJ.

Roberts, J. (2006). Limits to communities of practice. Journal of Management Studies, 43(3), 623-639. doi: 10.1111/j.1467-6486.2006.00618.x

Rouse, J. (2002). How scientific practices matter. Chicago: University of Chicago Press.

Schatzki, T. (2006). Organizations as they happen. Organization Studies, 27(12), 1863-1873. doi: $10.1177 / 0170840606071942$

Strati, A. (2007). Sensible knowledge and practice based learning. Management Learning, 38(1), 61-77. doi: $10.1177 / 1350507607073023$

Suchman, L. (2000). Organizing alignment: a case of bridge building. Organization, 7(2), 311-327. doi: $10.1177 / 135050840072007$

Thiry-Cherques, H. (2006). Pierre Bourdieu: a teoria na prática. Revista de Administração Pública, 40(1), 27-53. doi: 10.1590/S0034-76122006000100003

Turner, V. (1974). O processo ritual: estrutura e antiestrutura. Petrópolis: Vozes.

Wacquant, L. (2002). Corpo e alma: notas etnográficas de um aprendiz de boxe. Rio de Janeiro: Relume Dumará.

Wacquant, L. (2007). Esclarecer o habitus. Educação e Linguagem, 10(16), 63-71. Recuperado de https://www.metodista.br/revistas/revistas-ims/index.php/EL/article/viewArticle/126. doi: 10.15603/2176-1043/el.v10n16p63-71

\section{Dados dos Autores}

Marina Dantas de Figueiredo

Av. Washington Soares, 1321, Edson Queiroz, 60811-905, Fortaleza, CE, Brasil. E-mail: marina.dantas@ gmail.com

Neusa Rolita Cavedon

Rua Washington Luiz, 855, Centro, 90010-460, Porto Alegre, RS, Brasil. E-mail: nrcavedon@ea.ufrgs.br 